\title{
Affordances for learning linear functions: A comparative study of two textbooks from South Africa and Germany
}

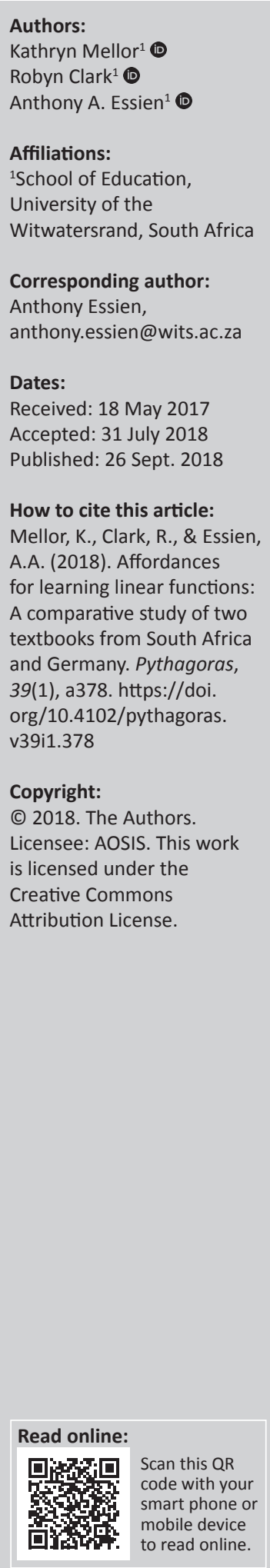

Textbook content has the ability to influence mathematical learning. This study compares how linear functions are presented in two textbooks, one of South African and the other of German origin. These two textbooks are used in different language-based streams in a school in Gauteng, South Africa. A qualitative content analysis on how the topic of linear functions is presented in these two textbooks was done. The interplay between procedural and conceptual knowledge, the integration of the multiple representations of functions, and the links created to other mathematical content areas and the real world were considered. It was found that the German textbook included a higher percentage of content that promoted the development of conceptual knowledge. This was especially due to the level of cognitive demand of tasks included in the analysed textbook chapters. Also, while the South African textbook presented a wider range of opportunities to interact with the different representations of functions, the German textbook, on the other hand, included more links to the real world. Both textbooks linked 'functions' to other mathematical content areas, although the German textbook included a wider range of linked topics. It was concluded that learners from the two streams are thus exposed to different affordances to learn mathematics by their textbooks.

\section{Introduction}

Mathematics textbooks have been found to have a strong influence on classroom practice (Fan, 2013; Howson, 1995; Stylianides, 2014; Valverde, Bianchi, Wolfe, Schmidt, \& Houang, 2002) and the tasks that they include can stimulate different levels of mathematical thinking and learning (Watson, \& Ohtani, 2015; Stein, Smith, Henningsen, \& Silver, 2000; Sullivan, Clarke, Clarke, \& O'Shea, 2010). At a South African school (the context of this study), learners in two language-based streams are taught mathematics using different textbooks up until the end of Grade 9. In Grade 10, however, learners who choose to write the National Senior Certificate examinations merge from both streams and are thereafter taught together. Although both groups of learners have encountered similar mathematical content en route to Grade 10, the textbooks utilised respectively in the two language-based streams do not necessarily approach this content in the same way. At the time the study was undertaken, one stream, which was taught in German according to the German Baden-Würtemberg curriculum, used the Elemente der Mathematik textbook series (Griesel, Postel, \& Suhr, 2005). The other, which was taught according to the South African CAPS curriculum, used Classroom Mathematics Grade 9 (Rhodes-Houghton et al., 2013). What sparked our interest in this study was the fact that the first author of this article was teaching Grade 9 Mathematics in the English stream at this school, with the knowledge that she would be moved to teach a Grade 10 class the subsequent year. It was thus imperative to understand the mathematics that learners were exposed to in the separate streams in preparation for teaching a merged Grade 10 class. Thus, in a larger study (Mellor, 2015), a comparative textbook analysis was undertaken as a means of attempting to interrogate the affordances for learning experienced by the two groups before progressing to Grade 10, with the ultimate aim of helping her, and other Grade 10 teachers at the school, have a deeper understanding of their learners' mathematical backgrounds, thus avoiding potential 'mathematical mismatches' between the teachers and their learners (Skemp, 1976).

The topic of functions was selected as the focus for the textbook analysis because it is generally agreed that functions form one of the most important unifying ideas in mathematics education (Knuth, 2000), and are ubiquitous in high school mathematics in general (Even, 1990). Emphasis is placed on the topic in both the South African and German curricula. Furthermore, various national 
assessments (such as the Annual National Assessment results for Grade 9 and the National Senior Certificate results for Grade 12) have indicated that the topic of functions is a recurring area of weakness for learners in South Africa (Department of Basic Education, 2012, 2013a, 2013b, 2014a, 2014b). As linear functions, specifically, is the first type of function studied in depth in both the South African and German mathematics curricula, it seemed an appropriate place to begin the investigation.

The overall purpose of this study was therefore to analyse and compare the manner in which linear functions are presented in the South African and German mathematics textbooks used at the observed school by learners en route to Grade 10. Due to variations between the South African and the German mathematics curricula adhered to in the two language-based streams, similar mathematical topics are not necessarily taught at the same grade level across the two streams. The topic of linear functions is introduced and taught as an area of focus in Grade 7 in the German stream while this occurs in Grade 9 in the English stream at the school. In order to compare textbook content on linear functions pitched at a similar level for purposes of this comparison, the English stream Grade 9 textbook, Classroom Mathematics Grade 9 (CM) was therefore paired with the German stream Grade 7 textbook, Elemente der Mathematik 3 (EDM). To this end, the study was informed by the following questions:

- How are linear functions presented in Classroom Mathematics Grade 9 and Elemente der Mathematik 3?

- What affordances for learning about linear functions are made available in Classroom Mathematics Grade 9 and Elemente der Mathematik 3?

It must be noted that this investigation did not aim to endorse either textbook's approach as superior. Furthermore, this study was not aimed at making any value judgements with regard to the academic strategy of using different language-based streams in the research school. Rather, the study intended to provide a thorough comparison of both textbooks' content originating in two different education systems, with the aim of understanding the affordances for learning made available to the two groups before progressing to Grade 10.

\section{The teaching and learning of functions}

It has been argued that the concept of functions is one of the most important in all mathematics (Dubinsky \& Harel, 1992). The topic lays a foundation for further study within the field of mathematics itself, while it also contributes as a tool in other subjects due to its capability to model phenomena in the real world (Ayalon, Lerman, \& Watson, 2013). Functions and graphs form one of the initial points in mathematics where learners encounter using one symbolic system to express and understand another (Leinhardt, Zaslavsky, \& Stein, 1990). Linear functions, in particular, form a crucial aspect in the learning of elementary algebra (Pierce, Stacey, \& Bardini, 2010). The study of functions is, however, often the point at which a learner may conclude that 'mathematics is meaningless and difficult' (Pierce, 2005). Schoenfeld (as cited in Leinhardt et al., 1990) argues that to avoid difficulties and misconceptions in the study of functions, a deep understanding of the correlation between the simplest form - a graphical line and its algebraic equation - is required.

When selecting criteria by which to compare the textbook content on linear functions and the affordances for learning made available to learners in the two textbooks, this study therefore investigated whether this fundamental topic is presented in a manner promoting procedural or conceptual knowledge, as well as how these types of knowledge are sequenced. Against this background, the integration of the multiple representations of functions, and the presence of links established between linear functions and the real world, as well as to other mathematical content areas, were also considered.

The debate as to whether procedural or conceptual knowledge should be predominantly promoted in mathematics instruction has been well documented over the past century (Hiebert \& Lefevre, 1986; Kilpatrick, Swafford, \& Findell, 2001; Piaget, 1978; Skemp, 1976). According to Hiebert and Lefevre (1986), the distinction between the two types of knowledge has generally juxtaposed formulaic skill against understanding. They describe procedural knowledge as knowledge that can be learnt by rote alone, while conceptual knowledge depends on the development of links and relationships. These ideas mirror Skemp's (1976) work on instrumental and relational understanding, which describes instrumental understanding as being made up of 'rules without reasons', while relational understanding is knowledge of 'what to do and why' (p. 23). These extremes lie at two poles of a continuum. Skemp considers these different types of knowledge as instructional goals that a teacher can direct their learners toward. Kilpatrick et al. (2001), however, argue that procedural fluency is vital to support conceptual understanding and to attain mathematical proficiency; thus, the two cannot be taught independently. Research on how learners develop procedural and conceptual knowledge has historically suggested four causal relationships (Rittle-Johnson \& Schneider, 2014): the 'concepts-first' view (which argues that children first learn conceptually and then derive procedural knowledge by repetition), the 'proceduresfirst' view (which suggests that children first learn procedure and thereafter learn concept in a process of abstraction), the 'inactivation' view (which posits that procedural and conceptual knowledge develop independently), and the 'iterative' view (which puts forward that the causal relationship is bi-directional). Of these, the 'iterative' view is the most commonly accepted (Rittle-Johnson \& Schneider, 2014). This study therefore attempted to investigate whether the linear functions content in the two textbooks predominantly promoted procedural or conceptual knowledge of linear functions, and how this (linear functions content) is sequenced in the two books under consideration. 
A distinctive aspect of the study of functions is its integration of different types of representations. In mathematics, representations include verbal, numerical, graphical and symbolic descriptions of a concept, which allow for it to be interpreted, communicated and discussed (Tripathi, 2008). Van Dyke and Craine (1997) contend that in the study of functions, it is critical that learners comprehend the underlying equivalence between the different representations: the same function can be represented in tabular, algebraic and graphical form. This is reiterated by Leinhardt et al. (1990), whose research indicates that school learners have difficulty in linking these various representations, resulting in compartmentalised knowledge that is not integrated into a coherent conceptual understanding of 'function'. Rider (2007) and Knuth (2000) argue that developing conceptual understanding of functions requires learners to understand their various representations, to understand the representations' respective strengths and weaknesses, and to be able to translate between them fluently. The desire that learners connect the various representations of a function is reminiscent of Hiebert and Lefevre's (1986) and Kilpatrick et al.'s (2001) definitions of conceptual knowledge which emphasise the importance of creating links between different segments of information. Utilising the different representations is like 'examining the concept through a variety of lenses, with each lens providing a different perspective that makes the picture (concept) richer and deeper' (Tripathi, 2008, p. 439). In this study, as previously indicated, the extent to which the various representations of functions are integrated in the two textbooks was therefore also interrogated.

A further criterion that contributes to the mathematical learning process is the use of contexts that link mathematics to the real world. The realistic mathematics education movement is a prime example of how using tasks that relate to the real world can be utilised as 'a source of learning mathematics' (Van den Heuvel-Panhuizen, 2000). By using instructional material that is connected to reality, mathematics is hoped to be 'imaginable', so that it can remain close to learners' experiences and be perceived as relevant to society. Particularly in terms of teaching functions, Leinhardt et al. (1990) suggest that using real-world applications serves the dual purpose of deepening understanding of the topic and 'perhaps increas $[i n g]$ students' motivation by giving familiar meanings to the problems they encounter' (p. 20). Durant and Garofalo (1994) furthermore describe that functions have traditionally been taught abstractly. This does not allow learners to perceive the context they originate from, nor to understand their usefulness. As such, the literature indicates that using learning material that relates to the real world in the teaching of functions can be viewed as a means of promoting learning. It can also contribute to developing 'productive disposition' (Kilpatrick et al., 2001) - having the ability to see the value of mathematics. In light of this, the two textbooks in this study were also examined in terms of the extent to which they created links between linear functions and the real world.

\section{Textbooks and tasks in the teaching and learning of mathematics}

As indicated previously, textbooks have been shown to have a large influence on classroom practice (Stylianides, 2014; Valverde et al., 2002) as they are designed to help teachers structure their teaching and suggest a pathway for learners to follow when exploring a topic (Johansson, 2005). Their influence has led to a wealth of literature on textbook analysis being developed over past decades (e.g. Fan \& Zhu, 2007; Shield \& Dole, 2013). Stylianides (2014) contends that textbooks can be analysed from various perspectives, among others the learner's perspective, the teacher's perspective or a mathematical perspective (in terms of examining a textbook's potential to aid learning). Fan (2013) argues that examining how a topic is presented in a textbook is only the first step - thereafter, causal issues need to be examined. For example, one could investigate why a particular textbook's way of treating a topic in a specific context may be better than another.

Mathematical tasks, in many ways the building blocks of mathematics textbooks, have also been a focus of much international research in past years. Watson and Ohtani (2015), for instance, posit that mathematical tasks can influence learners' learning as well as their perception of the nature of mathematics, and are in fact the 'bedrock of classroom life' (p. 3). Various frameworks exist that aid the classification of tasks. For example, Shimizu, Kaur, Huang and Clark (2010) differentiate tasks with categories such as 'complex', 'rich' or 'authentic'. Furthermore, the Task Types and Mathematics Learning Research Project in Australia classified tasks according to four types, namely exemplifying tasks, contextualised tasks, open-ended tasks and interdisciplinary tasks (Sullivan et al., 2010). In this study, however, Stein et al.'s (2000) task analysis guide was selected to classify tasks due to its appropriateness to investigate our research questions.

\section{Theoretical and analytical framework}

This study was framed theoretically and analytically by an adapted version of Stein et al.'s (2000) task analysis guide. This guide provides a framework by which to evaluate learning material in terms of the level of cognitive demand of tasks - the type of thinking required by learners to successfully solve problems. It is the cumulative effect of learners' engagement with instructional tasks that allows them to learn mathematics and forms their conception of the nature of mathematics and their perception of whether they can make personal sense of the subject (Stein et al., 2000).

As shown in Figure 1, the task analysis guide's four categories ('memorisation', 'procedures without connections', 'procedures with connections', and 'doing mathematics') are split into two sections, namely 'lower-level demands' and 'higher-level demands'. 'Lower-level demand' tasks include those that can be solved by memorisation or by 


\begin{tabular}{|c|c|c|c|}
\hline \multicolumn{4}{|c|}{ Stein et al.'s taxonomy } \\
\hline \multirow{2}{*}{ 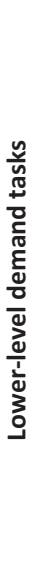 } & $\begin{array}{l}\text { Memorisation tasks have these features: } \\
\text { - They involve a reproduction of previously learnt facts, } \\
\text { formulae, rules or definitions. } \\
\text { - They cannot be solved using a procedure. } \\
\text { - They are not ambiguous - exact reproduction of previously } \\
\text { seen material. } \\
\text { - They have no connection to concepts or meanings that } \\
\text { underlie the fact, rules, formulae or definitions. }\end{array}$ & \multirow{2}{*}{ 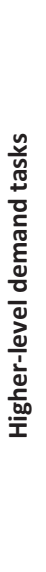 } & $\begin{array}{l}\text { Procedures with connection tasks have these features: } \\
\text { - They focus students' attention on the use of procedures for the purpose of } \\
\text { developing deeper levels of understanding. } \\
\text { - They suggest pathways to follow that are broad general procedures that } \\
\text { have close connections to underlying conceptual ideas. } \\
\text { - They make connections among multiple representations. } \\
\text { - Generally, procedures cannot be followed mindlessly. Learners need to } \\
\text { engage with the conceptual ideas that underlie the procedures. }\end{array}$ \\
\hline & $\begin{array}{l}\text { Procedures without connections tasks } \\
\text { - Are algorithmic. } \\
\text { - Have little ambiguity about what needs to be done. } \\
\text { - Have no connections to the concepts or meaning that } \\
\text { underlie the procedure. } \\
\text { - Focus on correct answer rather than understanding. }\end{array}$ & & $\begin{array}{l}\text { Doing mathematics are tasks that: } \\
\text { - Require complex and non-algorithmic thinking. } \\
\text { - Require students to explore and understand the nature of mathematical } \\
\text { concepts, processes or relationships. } \\
\text { - Demand self-monitoring or self-regulation of one's own cognitive processes. } \\
\text { - Require learners to access and use relevant knowledge and experiences. } \\
\text { - Require learners to analyse the task and actively examine task constraints } \\
\text { that may limit possible solution strategies and solutions. } \\
\text { - Require considerable cognitive effort and may involve some level of } \\
\text { anxiety due to the unpredictable nature of solution processes. }\end{array}$ \\
\hline
\end{tabular}

Source: Stein, M.K., Smith, M.P., Henningsen, M., \& Silver, E. (2000). Implementing standards-based mathematics instruction: A casebook for professional development. New York, NY: Teachers College Press (p. 16)

FIGURE 1: A summary of task analysis guide.

using procedures that can be applied independently of understanding the underlying concept (procedures without connections). 'Higher-level demand' tasks require the ability to use procedure in a manner that relies on an understanding of the underlying concept (procedures with connections) as well as tasks that are non-algorithmic and require learners to explore underlying concepts (doing mathematics).

This task analysis guide was for us the springboard from which to evaluate the opportunities for learning in this study's analysed textbook content. In order to engage with this study's research questions specifically, the guide was adapted using the literature on procedural and conceptual mathematical knowledge, while also considering literature on the multiple representations of functions. Firstly, the task analysis guide was used to investigate the interplay of procedural and conceptual knowledge in the two textbooks in the following manner: textbook elements that resonate with the description of 'lower-level demands' were described as promoting procedural knowledge, while those that resonate with the description of 'higher-level demands' were described as promoting conceptual knowledge. This use of the task analysis guide was based on the language used to describe procedural and conceptual knowledge by key theorists on the topic, particularly Hiebert and Lefevre (1986) and Kilpatrick et al. (2001). Hiebert and Lefevre describe procedural knowledge as knowledge that can be gained by rote learning and that can exist without being connected to any existing schemas, echoing the descriptions in Stein et al.'s (2000) 'lower-level demand' tasks. Furthermore, Hiebert and Lefevre describe conceptual knowledge as being rich in links, with connections to pre-existing knowledge. Such knowledge is gained by meaningful learning that promotes knowledge integration into existing schemas. Kilpatrick et al.'s description of conceptual knowledge, and Skemp's (1976) comparable description of 'relational understanding', also highlight conceptual knowledge's reliance on connections. This view of conceptual knowledge resonates well with the 'higher-level demand' categories in Stein et al.'s task analysis guide. Importantly, the task analysis guide category of 'procedures with connections' highlights that making links between multiple representations of mathematical ideas helps to develop mathematical meaning. Thus, with these adaptations, the task analysis guide allowed the linear functions textbook content to be analysed and then compared.

In addition, the Trends in International Mathematics and Science Study (TIMSS) textbook investigation (Valverde et al., 2002) guided this study's research methodology. The global TIMSS in the mid-90s investigated and compared how textbooks contribute to implementing education policy and curricular goals in 48 education systems. As the TIMSS research examined textbooks in terms of their educational opportunity with the goal to compare textbooks from different countries, their methodology resonates well with this study's aim of examining CM and EDM's linear functions content in terms of their affordances for learning. In the TIMSS, each analysed textbook chapter was partitioned into smaller units of analysis, called 'blocks', by separating content according to its purpose. Ten categories were used to differentiate the purpose of textbook content: narrative, related narrative, unrelated instructional narrative, related graphic, unrelated graphic, exercise set, unrelated exercise set, activity, worked example, and other. For example, a single textbook page in their study could have been made up of content with four different purposes, thus resulting in four separate blocks. Each block was then analysed as an individual component. The TIMSS methodology lent itself to be used in conjunction with the adapted version of Stein et al.'s (2000) task analysis guide for the purposes of this article's study, as it provided a means of delineating the selected textbook content into individual units that could then be classified and analysed.

\section{Research design and methodology}

The approach used in the larger study (Mellor, 2015) was as follows: once the relevant chapters on linear functions were 
identified in CM and EDM, their contents were examined and then compared by means of a qualitative content analysis. The first step in this process was to partition the selected chapters into much smaller units of analysis. To do so, the content of each selected page was segmented into various 'blocks' of information, separated by their purpose. The five purpose categories in Table 1 were used.

After the chapters had been partitioned into 'blocks', each individual block was then coded so that the content could be accurately described, allowing for analysis to take place thereafter. Making use of the adapted task analysis guide, as described above, each block was first coded as promoting conceptual or procedural knowledge of linear functions. During this coding process, we realised that Stein et al.'s (2000) four categories were not sufficient to code all textbook content. Although this method was effective to code exercises and worked examples, it did not cater for sections of instructional narrative or graphics. In light of this, a fifth category was added (a posteriori) to the original categories of the task analysis guide. It was titled 'reading for understanding'. When coding content that fell into this

TABLE 1: The different purposes of textbook content used to partition the selected chapters.

\begin{tabular}{|c|c|}
\hline Purpose & Description \\
\hline $\begin{array}{l}\text { Instructional } \\
\text { narrative }\end{array}$ & $\begin{array}{l}\text { Written language (that may incorporate mathematical symbols) that } \\
\text { presents or explains mathematical content }\end{array}$ \\
\hline Graphic & $\begin{array}{l}\text { A picture, diagram or graph that is incorporated to complement the } \\
\text { instructional narrative }\end{array}$ \\
\hline Exercise & Unsolved mathematical tasks that the learner should attempt \\
\hline $\begin{array}{l}\text { Worked } \\
\text { example }\end{array}$ & $\begin{array}{l}\text { Solved mathematical tasks that aim to provide instruction or } \\
\text { explanation }\end{array}$ \\
\hline Other & Any content that does not fit the above criteria \\
\hline
\end{tabular}

Source: Mellor, K. (2015). An analysis of linear functions in a South African and a German textbook: Prospects and possibilities. Unpublished B.Sc. (Hons) Research Report, University of the Witwatersrand, Johannesburg, South Africa (p. 18) category, we drew on both the ideas in the task analysis guide and the literature on procedural and conceptual knowledge to determine if it promoted procedural or conceptual knowledge. After coding for procedural or conceptual knowledge, each block was then coded according to the representations of functions included in the block. The following representations of functions were considered: flow diagram, table, equation, graph, ordered pairs, and words. Finally, each block was also coded in terms of whether it made links to other mathematical content areas (for example, geometry, area, etc.) or to the real world (Mellor, 2015). In order to promote validity and reliability of the coding process, two inter-raters provided feedback on the coding, and discrepancies were resolved by discussion.

Table 2 illustrates a selection of content 'blocks' similar to those found in the analysed chapters, as well as how these were coded. Once all relevant textbook content had undergone this coding procedure, analysis of the data took place.

\section{Analysis and discussion of findings}

Valverde et al. (2002) differentiate between a textbook's macrostructure - broad features of the book as a whole - and its microstructures - the features of individual chapters. Although not the focus of this study, a brief summary of the two textbooks' macrostructures is included to provide context for the detailed analysis of the elected chapters' microstructures thereafter. The analysis of the microstructures focuses on the affordances for learning presented in the textbooks regarding the interplay between procedural and conceptual knowledge, the integration of the multiple representations of functions and links established to other mathematical content areas and the real world.

TABLE 2: Examples of the types of content 'blocks' found in Classroom Mathematics Grade 9 and Elemente der Mathematik 3, and how these were coded.

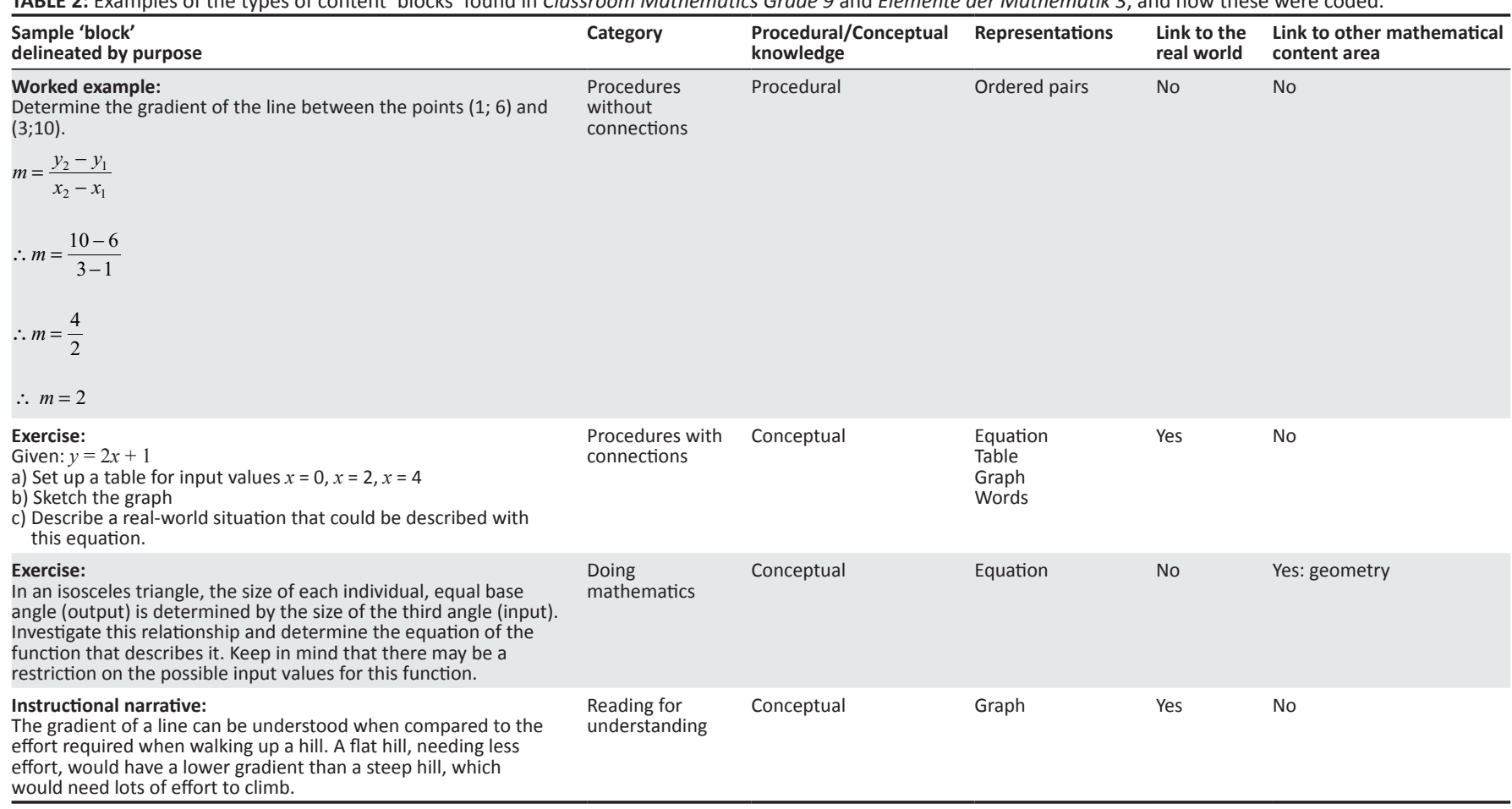




\section{Individual textbook contexts: The macrostructures}

The two textbooks differ markedly in terms of their macrostructures. Classroom Mathematics Grade 9 has 27 chapters overall, three of which relate to linear functions. These three chapters are located at different points in the book. In comparison, Elemente der Mathematik 3 is made up of only six chapters overall with one chapter on linear functions. Although a similar total number of pages are dedicated to linear functions in both books, the pages are set out in a contrasting manner: when segmenting the chapters for analysis, CM had 78 blocks across the 38 analysed pages, while EDM had 166 blocks in its 39-page chapter. The content of EDM is thus far denser, with EDM having about double the number of content blocks of $\mathrm{CM}$ within a similar amount of space. A further analysis of these content blocks follows in the next section.

\section{Microstructure: Interplay of procedural and conceptual knowledge}

Of CM's 78 content blocks, just over half were coded as promoting procedural knowledge $(54 \%)$ while only about a third of EDM's 166 blocks were coded as procedural (37\%). As is visible in Figure 2, both textbooks appear to adopt Hiebert and Lefevre's (1986) view of a mathematically competent learner in the sense that they promote a combination of both conceptual and procedural knowledge. Additionally, Kilpatrick et al.'s (2001) view on mathematical proficiency is helpful in making sense of the different foci of the respective chapters: when it comes to linear functions, CM does not promote conceptual understanding as much as EDM does.

With the aim of gaining a more holistic understanding of how the respective textbooks utilise conceptual and procedural knowledge, the linear sequencing of the content was also analysed. As indicated earlier, the chapters on linear functions are arranged differently in the two textbooks: CM has three chapters inserted at different locations of the textbook while

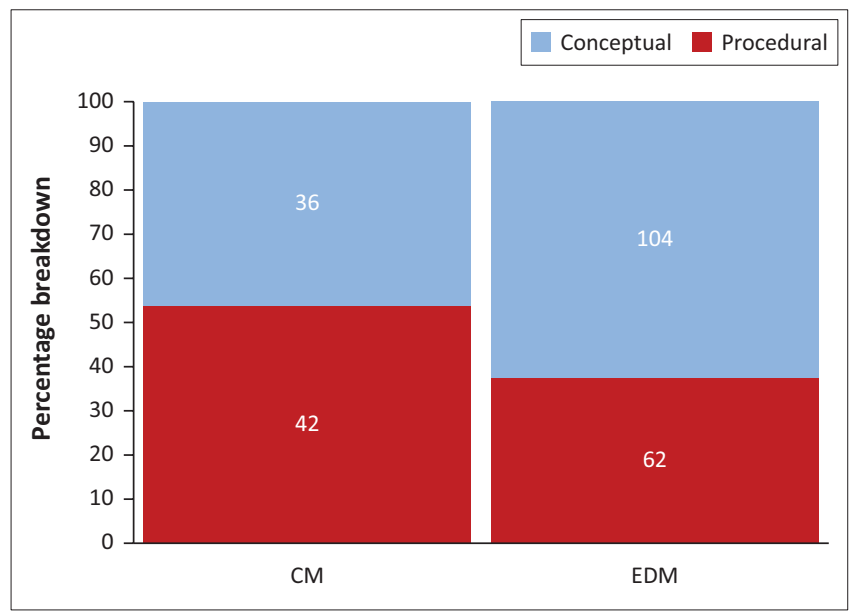

Source: Mellor, K. (2015). An analysis of linear functions in a South African and a German textbook: Prospects and possibilities. Unpublished B.Sc. (Hons) Research Report, University of the Witwatersrand, Johannesburg, South Africa (p. 27)

CM, Classroom Mathematics Grade 9; EDM, Elemente der Mathematik 3.

FIGURE 2: Comparison of blocks that promote procedural and conceptua knowledge in Classroom Mathematics Grade 9 and Elemente der Mathematik 3. The number of blocks coded in each category per book is also given.
EDM has only one chapter with six subsections. Examining the linear sequencing of the coded content blocks in the separate sections highlighted the interplay between the individual blocks (Mellor, 2015). Figure 3 depicts these relationships. For example, Chapter 7 of CM (Functions and Relationships 1) begins with three content blocks that were coded as promoting conceptual knowledge, and ends with three content blocks that were coded as promoting procedural knowledge.

Analysis of the three chapters of CM did not indicate a consistent method of arranging content that promotes procedural and conceptual knowledge. The chapters 'Functions and Relationships 1' and 'Functions and Relationships 2' can be viewed as a unit as they cover the same content. Mellor (2015) explains further as follows:

It therefore appears that in these two chapters the content is arranged predominantly according to the 'concepts-first' view. This view posits that learners first acquire knowledge of concepts and use this as a foundation to develop procedural knowledge (Rittle-Johnson \& Schneider, 2014). Contrastingly, the chapter on 'Graphs' appears to subscribe to the 'iterative' view of the development of conceptual and procedural knowledge. This suggests that the causal relationship between conceptual and procedural knowledge is bi-directional, where an increase in conceptual knowledge influences procedural knowledge and vice versa (Rittle-Johnson \& Schneider, 2014). This view is particularly in line with Kilpatrick et al.'s (2001) view of mathematical proficiency that suggests that conceptual and procedural understanding (as well as their other three strands) are interdependent and develop in conjunction with each other. (p. 28)

In EDM, there appears to be a more consistent pattern of content blocks supporting concept or procedure. Like the 'Graphs' chapter in CM, the subsections of the Linear Functions chapter also indicate a predominantly 'iterative' view, with procedural and conceptual knowledge being more consistently integrated. There is, however, also a trend of the subsections beginning with conceptual content. As a whole, the content of EDM appears to combine conceptual and procedural content more consistently than CM across the analysed chapters (Mellor, 2015).

Further points of interest regarding the pattern of EDM's content in Figure 3 occur at the noticeable clusters of conceptual or procedural blocks. These occur at the end of subsections 6.1, 6.2, 6.3 and 6.5, and in the first half of subsection 6.6. A closer examination reveals that in the clusters for subsections 6.2 and 6.3 , this is solely due to the nature of the 'regular' exercises at that point. In 6.1, 6.5, and 6.6, however, the conceptual clusters are due in part to longer, special investigative tasks that invite learners to explore the topic of linear functions. These small sections, entitled 'Im Blickpunkt' [In Focus] present content to extend learners such as using graphical calculators to work with linear functions, learning about the line of best fit, or using functions to investigate how to save electricity. Classroom Mathematics Grade 9 does not include this type of enrichment content, 


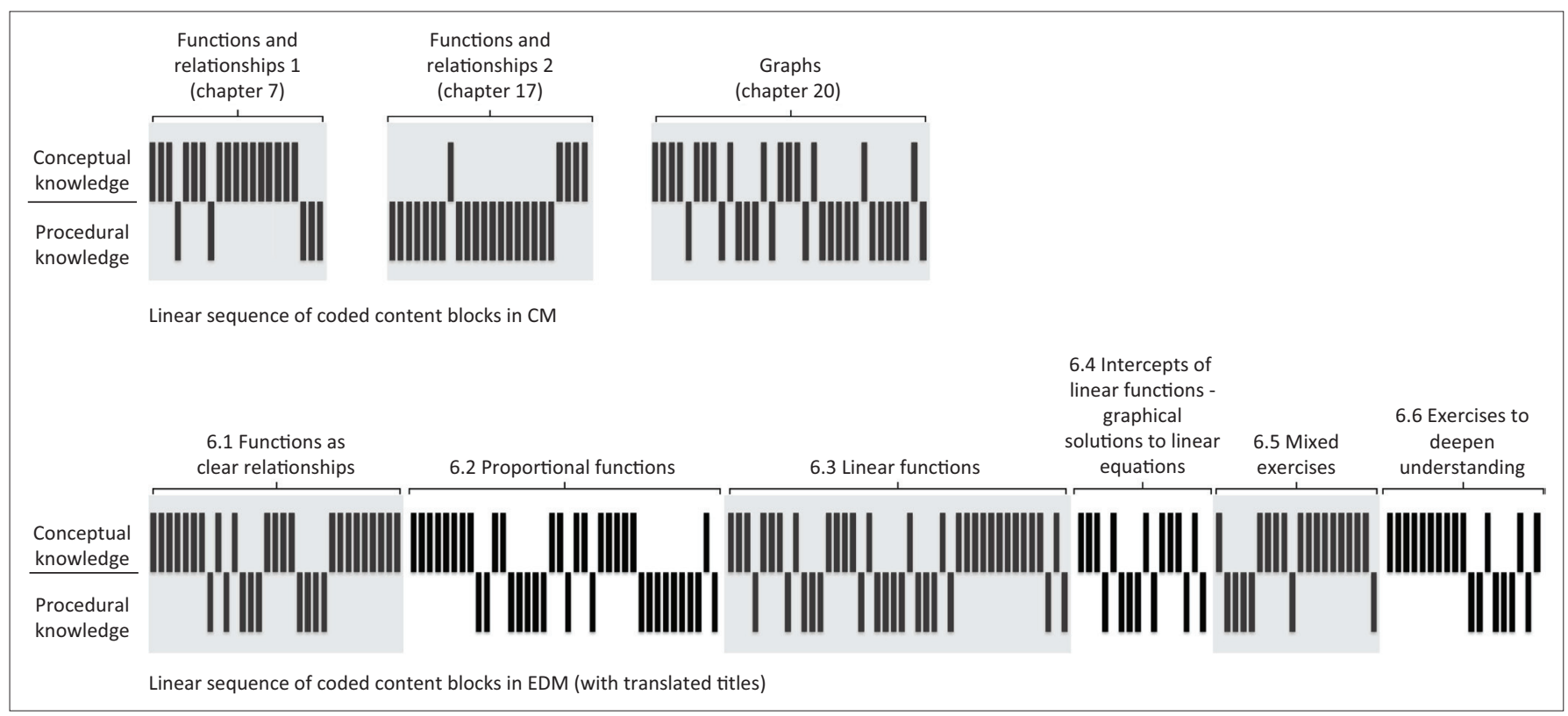

Source: Mellor, K. (2015). An analysis of linear functions in a South African and a German textbook: Prospects and possibilities. Unpublished B.Sc. (Hons) Research Report, University of the Witwatersrand, Johannesburg, South Africa (p. 28)

CM, Classroom Mathematics Grade 9; EDM, Elemente der Mathematik 3.

FIGURE 3: Analysis of coded content blocks, sequenced as in the respective chapters, in terms of procedural and conceptual knowledge.

which is a contributing factor to the two textbooks' contrasting proportional breakdowns of content that promotes conceptual and procedural knowledge (see Figure 2).

Analysis of individual content blocks provided further explanation of the different approaches to conceptual and procedural knowledge found in the two textbooks. Figure 4 provides a summary of the coded content blocks from both chapters in terms of their cognitive demand. Classroom Mathematics Grade 9 has noticeably more content that promotes 'procedures without connections', while EDM has more 'procedures with connection' and 'doing mathematics' content. No content blocks in either book were categorised as 'memorisation'. 'Reading for understanding' content was categorised almost exclusively as promoting conceptual understanding in both CM and EDM, and made up a similar percentage of content. The remaining content blocks in the compared chapters are made up predominantly of exercises and, to a lesser extent, worked examples. Thus, it can be argued that it is the nature of the tasks that these textbook chapters include (in terms of exercises and worked examples) that influences the type of mathematical knowledge that the two books promote.

Comparing specifically selected tasks from the two textbooks indicated that although the two textbooks include similar tasks with similar desired outcomes, the level of cognitive demand of the tasks is generally higher in EDM than in CM. Consider the following comparison between Figures 5 and 6 .

The tasks in Figures 5 and 6 test similar content knowledge - that of being able to represent functions in four different ways (albeit with CM investigating only one function and EDM investigating four different functions). Both questions

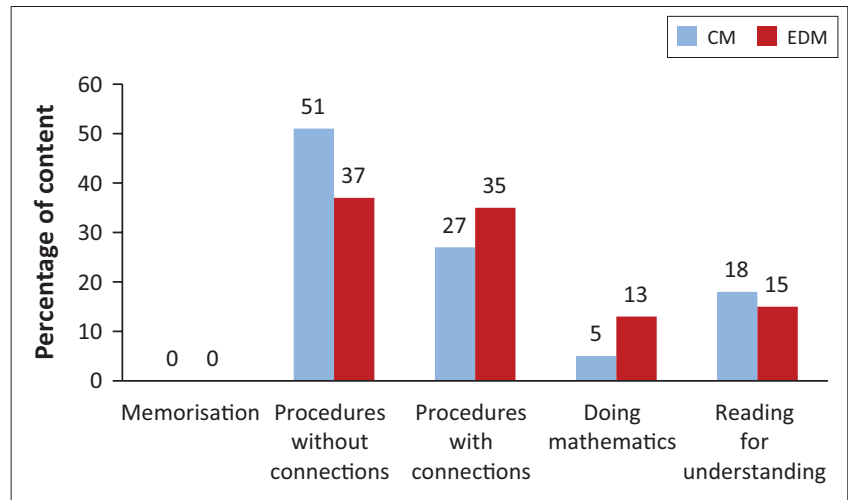

Source: Mellor, K. (2015). An analysis of linear functions in a South African and a German textbook: Prospects and possibilities. Unpublished B.Sc. (Hons) Research Report, University of the Witwatersrand, Johannesburg, South Africa (p. 29)

CM, Classroom Mathematics Grade 9; EDM, Elemente der Mathematik 3.

FIGURE 4: Comparison of each category used in the coding process for procedural and conceptual knowledge.

6. The relationship between input and output values is given in the table below.

\begin{tabular}{|c|c|c|c|c|c|c|c|}
\hline Input value $(\boldsymbol{x})$ & -3 & -2 & -1 & 0 & 1 & 2 & 3 \\
\hline Output value $(\boldsymbol{y})$ & -11 & -8 & -5 & -2 & 1 & 4 & 7 \\
\hline
\end{tabular}

a) Write down an algebraic rule which represents the relationship.

b) Use the table to represent the relationship as ordered pairs.

c) Represent the relationship by means of a flow diagram.

d) Represent the relationship graphically for the input values in the table.

Source: Rhodes-Houghton, R., Aird, J., Brownbill, C., Essack, R., Hoole, S., Kitto, A., ... Van Duyn, J. (2013). Classroom Mathematics Grade 9: Learner's Book. Johannesburg: Heinemann (p. 229)

FIGURE 5: Translating between function representations in Classroom Mathematics Grade 9.

appear toward the end of their respective chapter or section. However, Figure 5 promotes 'procedures without connections' (thus contributing to content that promotes procedural knowledge), while Figure 6 promotes 'procedures with connections' (thus contributing to content that promotes conceptual knowledge). Schoenfeld, Smith and Arcavi (1993) 
(as cited in Schwarz \& Dreyfus, 1995) state that if tasks focus on translating between representations of functions in a manner that becomes highly procedural, this skill no longer contributes considerably to conceptual understanding. This is in line with the classification description in the task analysis guide which states that tasks should be classified as 'procedures without connections' if the required procedure is evident 'based on ... placement of the task' (Stein et al., 2000, p. 16). In the set of exercises that lead up to and include the task in Figure 5, the act of translating between representations does become very procedural. Furthermore, the task only requires one functional relationship to be manipulated, and uses only a table presenting consecutive integers as its starting point, reducing opportunity for conceptual links to be developed. In comparison, the task in Figure 6 requires learners to engage simultaneously with four 'starting points' when manipulating representations in a layout that highlights the interplay between them. Additionally, the provided table form of the function goes up in twos, and the respective functions need to be linked to a real-world context. Both these aspects contribute to the task's potential to strengthen conceptual understanding. As argued in Mellor (2015), the comparison of these two tasks thus illustrates how similar content can be presented in a manner that creates different affordances to strengthen procedural or conceptual understanding thereof.

The use of graded questions also differs in the two textbooks' linear functions content. Both books include a highly similar task on isosceles triangles that requires learners to describe the functional relationship between the base angles and the third angle. These two tasks are provided in Figures 7 and 8.

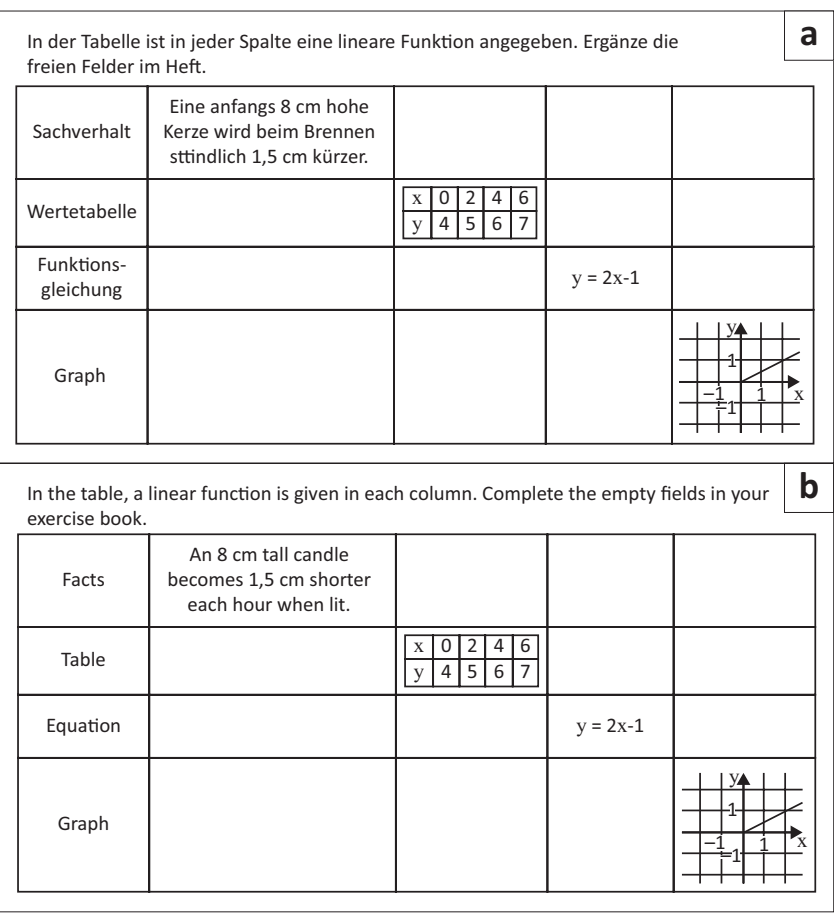

Source: Adapted from Griesel, H., Postel, H., \& Suhr, F. (2005). Elemente der Mathematik 3 : Baden-Würtemberg. Braunschweig: Schroedel (p. 239)

Note: Translation in (b) by K.M.

FIGURE 6: Task from Elemente der Mathematik 3 on translating between function representations, (b) translation of the task.
The comparison between the exercises in Figures 7 and 8 again highlights a notable difference between the manner in which the two textbooks pose their tasks: in CM, the tasks often include sub-questions that guide the learner while in EDM, this occurs less frequently. In this particular case, the task in Figure 7 is a 'procedures with connections' task as although it does develop deeper levels of understanding, it clearly suggests pathways for learners to follow that remove it from the category of 'doing mathematics'. In comparison, the exercise in Figure 8 gives little guidance to the learner, thus promoting non-algorithmic thinking and metacognition. Here, learners could perhaps come to realise on their own how useful the tabular form of a function can be. This would arguably have more impact on their conceptual (and procedural) understanding than being explicitly told to create one as in iii) of Figure 7. This comparison thus exemplifies how the use of sub-questions can lead to a decline in the cognitive demand of a task.

The comparisons between Figures 5 and 6 and Figures 7 and 8 provide a potential explanation of the discrepancies between the two textbooks highlighted by the coding process depicted in Figure 3: although the contents tested are in many respects similar, the manner in which the tasks are designed contributes to their ability to promote either conceptual or procedural knowledge and thus influences the affordances for learning made available in the books. We acknowledge

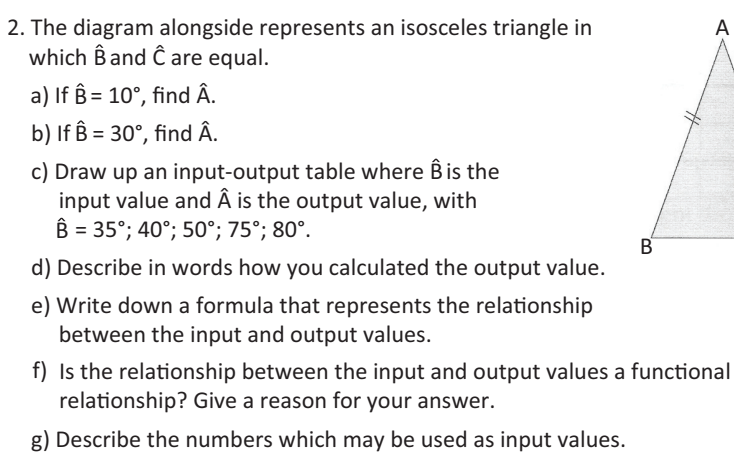

Source: Rhodes-Houghton, R., Aird, J., Brownbill, C., Essack, R., Hoole, S., Kitto, A., ... Van Duyn, J. (2013). Classroom Mathematics Grade 9: Learner's Book. Johannesburg: Heinemann (p. 98)

FIGURE 7: Task from Classroom Mathematics Grade 9 on isosceles triangles.

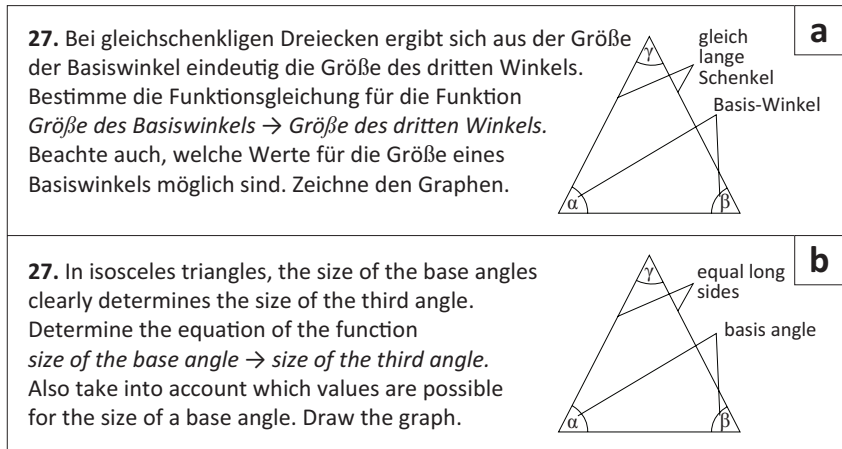

Source: Griesel, H., Postel, H., \& Suhr, F. (2005). Elemente der Mathematik 3: BadenWürtemberg. Braunschweig: Schroedel (p. 232)

Note: Translation in (b) by K.M.

FIGURE 8: Task from Elemente der Mathematik 3 on isosceles triangles, (b) translation of the task. 
that these examples were hand-picked and that bias affected the choices. However, after having engaged deeply with the content of the two textbooks, we concluded that these are representative examples of how the two books set their tasks. Classroom Mathematics Grade 9 does, therefore, appear to set tasks of a lower cognitive demand than EDM although the task content outcomes are largely similar. This could therefore be a strong contributing factor to the proportional breakdown of procedural and conceptual knowledge in the chapters being compared.

\section{Microstructure: Integration of the multiple representations of functions}

Both the task analysis guide (Stein et al., 2000) and Kilpatrick et al. (2001) stress that in mathematics using multiple representations is an indication of conceptual understanding. This is especially the case in terms of the study of functions, where an understanding of their various forms is an integral aspect of the topic (Knuth, 2000; Leinhardt et al., 1990; Van Dyke \& Craine, 1997). In light of this, we examined how the two textbooks integrate various representations of functions (flow diagram, table, equation, graph and words) into each content block of the analysed chapters. The manner in which this is done creates different affordances for learning linear functions. The results of this investigation are presented in Figure 9.

The two textbooks have different foci in terms of multiple representations. About half of CM's content blocks make use of only one representation of functions. Of this, the notable contributors are 'graph only' questions ( $28 \%$ of total blocks) while 'equation only' questions make up about $15 \%$ of all content blocks. The next most frequent category is shared between blocks that integrate two and three representations, each making up about a fifth of total blocks. Finally, just over $10 \%$ of blocks incorporate either four or five representations. This indicates that although there is a clear focus on content that involves either graphs or equations, the book does place importance on integrating other representations into its content. In comparison, only about a fifth of EDM's content

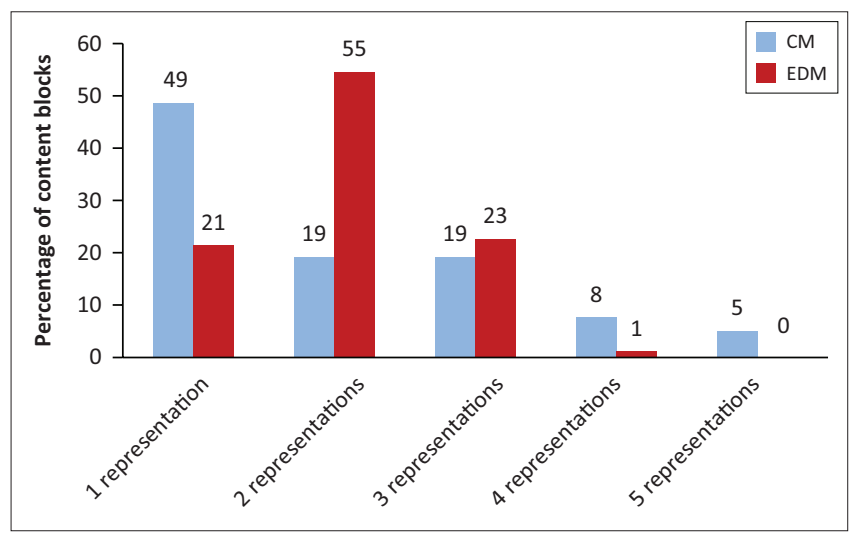

Source: Mellor, K. (2015). An analysis of linear functions in a South African and a German textbook: Prospects and possibilities. Unpublished B.Sc. (Hons) Research Report, University textbook: Prospects and possibilities. Unpublished B.Sc. (Hons
of the Witwatersrand, Johannesburg, South Africa (p. 33)

CM, Classroom Mathematics Grade 9; EDM, Elemente der Mathematik 3.

FIGURE 9: Percentage of content blocks that utilise one or more function representations (flow diagram, table, equation, graph, written words). blocks utilise just one representation. Over half of its content blocks integrate two representations of functions. This modal category is composed overwhelmingly of content blocks that combine graphs and equations (45\%). Blocks that utilise three representations make up its second highest category (just over $20 \%$ of the data) with only 2 out of the 166 coded blocks using four representations. Thus, although CM focuses on individual skills related to linear functions more than EDM does, the book also emphasises translating between three or more representations to a higher degree than the German book: a third of CM's coded content integrates three or more representations while only a quarter of EDM's content encourages this.

As indicated previously, the ability to translate between multiple representations in mathematics is seen to contribute toward conceptual understanding (Kilpatrick et al., 2001). It was therefore surprising that although $\mathrm{CM}$ includes many tasks that integrate multiple representations, analysis of the chapter as a whole indicated a predominance of procedural knowledge. Translating between multiple representations can, however, become highly procedural if focused on repeatedly in the same fashion. Tasks such as in Figure 5 occur frequently in CM, in both the exercises and worked examples, which contributed to these content blocks being coded as promoting procedure. This can, however, hold value as Kilpatrick et al. (2001) describe:

Without procedural fluency, students have trouble deepening their understanding of mathematical ideas or solving mathematical problems. The attention they devote to working out results they should ... compute easily prevents them from seeing important relationships. (p. 122)

Translating between the multiple representations of functions is an acknowledged weakness in high school mathematics (Leinhardt et al., 1990; Rider, 2007) and it thus appears that in $\mathrm{CM}$, this skill is being promoted to the point that it becomes procedural. If learnt with understanding, this would hopefully lead to flexible mathematical knowledge where learners can use the various representations to their advantage. Thus, if the conceptual links behind the translations are stressed in the classroom rather than purely the procedural steps, the content of CM has the potential to allow learners to translate between the representations of functions in a manner where this becomes second nature.

Although the content of EDM does not promote the translation between representations to the point that $\mathrm{CM}$ does, the book focuses in depth on the relationship between linear functions and solving linear equations. Consider, for example, the task in Figure 10.

Such a task has the potential to develop strong connections and deep understanding of the relationship between linear equations and linear graphs. Although EDM may not develop the procedural fluency that CM does in translating between representations of functions, tasks such as this present the opportunity for procedural steps to be understood conceptually 


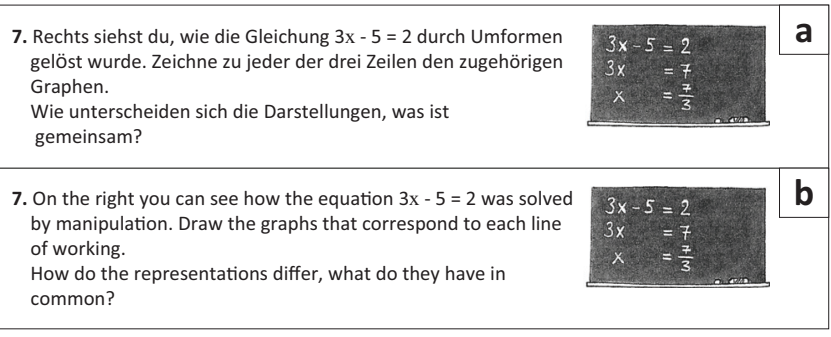

Source: Griesel, H., Postel, H., \& Suhr, F. (2005). Elemente der Mathematik 3: BadenWürtemberg. Braunschweig: Schroedel (p. 236)

Note: Translation in (b) by K.M.

FIGURE 10: (a) Task from Elemente der Mathematik 3 linking linear graphs to linear equations, (b) translation of the task.

in a manner that was not evident in CM. Thus, overall, EDM can be seen as promoting deep, interconnected knowledge of linear functions in equation, graphical and tabular form, while CM promotes procedural fluency in a broader range of representations.

\section{Microstructure: Links from linear functions to other mathematical topics and the real world}

Hiebert and Lefevre (1986) argue that conceptual understanding of a mathematical topic comes about when 'the holder recognises its relationship to other pieces of information' (p. 4). Apart from 'internal' links between multiple representations, the tasks discussed in Figures 7 and 8 illustrated how both books have used linear functions to add meaning to the study of isosceles triangles (and vice versa). The two textbooks are quite similar in this regard, with both linking individual tasks to topics such as rate, area or volume, number systems and patterns in similar ways. As discussed, EDM also particularly emphasises the connection between linear functions and solving linear equations to deepen conceptual understanding of both topics. The textbook also touches on the concept of linear regression toward the end of the chapter, suggesting the use of linear functions in statistical analysis and prediction. In terms of linking functions to other mathematical topics to deepen conceptual understanding, both books include opportunities to do this, although EDM does so to a stronger degree than CM.

However, although these types of links have the potential to develop learners' conceptual understanding of mathematical content, they do not necessarily contribute to the learners' understanding of the value of linear functions, nor how functional relationships manifest themselves in the real world. While perhaps not originally meant in this sense, Hiebert and Lefevre's (1986) description of conceptual understanding, cited above, could go beyond the realm of content knowledge to include a concept's relationship to and value in the real world. As Kilpatrick et al. (2001) argue in their discussion of mathematical expertise, conceptual and procedural knowledge are just two strands of being mathematically proficient - understanding why the learned knowledge is worthwhile is another (they call this aspect of mathematical proficiency 'productive disposition'). Incorporating realworld contexts can contribute to learners perceiving mathematics as useful and relevant (Durant \& Garofalo, 1994; Leinhardtet al., 1990; Van den Heuvel-Panhuizen, 2000).
In terms of including content that demonstrates the use of linear functions in the real world, EDM and CM use different approaches. EDM includes more blocks linked to the real world than CM $-32 \%$ of content blocks in EDM compared to $24 \%$ in CM. Furthermore, their placement of these blocks is not the same, particularly in terms of how the chapters are introduced. Elemente der Mathematik 3 uses real-world situations in the majority of its worked examples that form the introduction to the chapter's individual subsections. In comparison, CM does not use real-world contexts in its introductions (or worked examples). These contrasting introductory styles begin the chapters with different tones. In EDM, the mathematical content is used to make sense of realistic contexts, while in $\mathrm{CM}$, the mathematics is positioned as being quite abstract and part of a pre-existing system to be learned. Elemente der Mathematik 3 therefore appears to illustrate the real-world value of linear functions to a higher degree than CM. Overall, the analysis indicated that EDM promotes the interlinking of topics to a higher degree than $\mathrm{CM}$, both in terms of links between mathematical topics and links between mathematics and the real world.

\section{Conclusion and implications}

This study has argued that CM and EDM create different affordances for learning about linear functions. Both textbooks provide opportunity to learn about linear functions procedurally and conceptually, but with different emphases. Elemente der Mathematik 3 presents this content in a more conceptual manner whereas CM presents the work more procedurally. Analysis indicated that this difference was evidenced by the cognitive demand of the included exercises. CM's use of guiding questions and the (at times) repetitive nature of the tasks led to promoting knowledge of a predominantly procedural nature. Contrastingly, EDM included more tasks that provided opportunity for linear functions to be engaged with conceptually. The textbooks' approaches to sequencing content in terms of procedural and conceptual knowledge also differs, with CM making use of both 'concepts first' and an 'iterative' arrangement of content while EDM appears to consistently use an 'iterative' approach, although with a trend of beginning individual subtopics more conceptually.

This study also found that CM includes a broader range of function representations than EDM. However, CM also includes a higher percentage of tasks that only deal with one type of representation. In comparison, over half of EDM's coded content links two types of representations, predominantly linear equations to graphical representations of functions. In general, the findings indicated that although the German book covers fewer representations, those included are studied more in depth and conceptually than is apparent in CM.

Lastly, EDM creates more links between linear functions and other mathematical content areas as well as to the real world than CM does. According to Hiebert and Lefevre (1986) and Skemp (1976), conceptual knowledge is developed when 
links and connections are created to existing mathematical knowledge. This suggests that learners using EDM are more likely to have greater affordances to integrate the topic of linear functions conceptually with their existing mathematical knowledge than learners using CM (Mellor, 2015). Also, EDM's many links to the real world, particularly in introductory content, may provide additional affordances to learn, as working on realistic problems is considered to aid learners' development of mathematical tools and understanding (Van den Heuvel-Panhuizen, 2000).

Overall, this study has exhibited that two different textbooks can present the topic of linear functions in different ways, and thus create different affordances for this content to be learnt. At the school where these textbooks were used in two language-based streams, learners entering a combined class in Grade 10 were thus exposed to different methods of making sense of mathematics. What do these findings mean for a teacher who is tasked with teaching Grade 10 learners in such a school? We argue that the key to successfully teaching learners in a combined class is the awareness and acknowledgement of the different affordances learners have been exposed to in terms of their mathematics content prior to Grade 10. This awareness may mean tailoring lesson plans by using the types of examples from the German book that would benefit the English stream learners, and vice versa.

\section{Acknowledgements}

K.M. thanks the University of the Witwatersrand for the Postgraduate Merit Award that provided financial support during the course of this research. The article is based on the B.Sc. Honours research report of K.M. which was jointly supervised by R.C. and A.A.E.

\section{Competing interests}

The authors declare that they have no financial or personal relationships that may have inappropriately influenced them in writing this article.

\section{Authors' contributions}

K.M. wrote the majority of the article. All three authors contributed to the conceptualisation of the methodological approach used in the study. Data analysis was carried out by K.M., R.C. and A.A.E. based on the jointly developed analytical framework.

\section{References}

Ayalon, M., Lerman, S., \& Watson, A. (2013). Development of students' understanding of functions throughout school years. In C. Smith (Ed.), Proceedings of the British Society for Research into Learning Mathematics (Vol. 33, no. 2, pp. 7-12) Retrieved from http://www.bsrlm.org.uk/wp-content/uploads/2016/02/BSRLM IP-33-2-02.pdf

Department of Basic Education. (2012). Diagnostic report: Annual national assessment 2012. Pretoria: DBE.

Department of Basic Education. (2013a). Report on the annual national assessment of 2013. Grade 1-6 \& 9. Pretoria: DBE.

Department of Basic Education. (2013b). National senior certificate examination 2013: Diagnostic report. Pretoria: DBE.
Department of Basic Education. (2014a). Diagnostic report: Annual national assessment 2014. Intermediate and senior phase. Pretoria: DBE.

Department of Basic Education. (2014b). National senior certificate examination 2014: Diagnostic report. Pretoria: DBE.

Dubinsky, E., \& Harel, G. (1992). The nature of the process conception of function. In G. Harel \& E. Dubinsky (Eds.), The concept of a function: Aspects of epistemology and pedagogy (pp. 85-106). Washington, DC: Mathematical Association of America.

Durant, K., \& Garofalo, J. (1994). Teaching functions and graphing in pre-calculus mathematics. Journal of Developmental Education, 18(1), 18-24. Retrieved from http://www.jstor.org/stable/i40105115

Even, R. (1990). Subject matter knowledge for teaching and the case of functions. Educational Studies in Mathematics, 21(6), 521-554. https://doi.org/10.1007/ BF00315943

Fan, L. (2013). Textbook research as scientific research: Towards a common ground on issues and methods of research on mathematics textbooks. ZDM: The International Journal on Mathematics Education, 45(5), 765-777. https://doi.org/10.1007/ s11858-013-0530-6

Fan, L., \& Zhu, Y. (2007). Representations of problem-solving procedures: A comparative look at China, Singapore, and US mathematics textbooks. Educational Studies in Mathematics, 66(1), 61-75. https://doi.org/10.1007/s10649-006-9069-6

Griesel, H., Postel, H., \& Suhr, F. (2005). Elemente der Mathematik 3: BadenWürtemberg. Braunschweig: Schroedel.

Hiebert, J., \& Lefevre, P. (1986). Conceptual and procedural knowledge in mathematics: An introductory analysis. In J. Hiebert (Ed.), Conceptual and procedural knowledge: The case of mathematics (pp. 1-27). Hillsdale, NJ: Lawrence Erlbaum Associates.

Howson, G. (1995). Mathematics textbooks: A comparative study of grade 8 texts. Vancouver: Pacific Education Press.

Johansson, M. (2005). Mathematics textbooks - The link between the intended and the implemented curriculum. In Proceedings of the Eighth Internationa Conference: Reform, Revolution and Paradigm Shifts in Mathematics Education (pp. 119-123). Johor Bharu, Malaysia: Mathematics Education into the 21st Century Project. Retrieved from http://math.unipa.it/ grim/21_project/21_ malasya_Johansson119-123_05.pdf

Kilpatrick, J., Swafford, J., \& Findell, B. (2001). Adding it up: Helping children learn mathematics. Washington, DC: National Academy Press.

Knuth, E.J. (2000). Understanding connections between equations and graphs. The Mathematics Teacher, 93(1), 48-53. Rerieved from https://www.jstor.org/ stable/27971259

Leinhardt, G., Zaslavsky, O., \& Stein, M.K. (1990). Functions, graphs and graphing: Tasks, learning and teaching. Review of Educational Research, 60(1), 1-64. https:// doi.org/10.3102/00346543060001001

Mellor, K. (2015). An analysis of linear functions in a South African and a German textbook: Prospects and possibilities. Unpublished B.Sc. (Hons) Research Report University of the Witwatersrand, Johannesburg, South Africa.

Piaget, J. (1978). Success and understanding. Cambridge, MA: Harvard University Press.

Pierce, R. (2005). Linear functions and a triple influence of teaching on the development of students' algebraic expectation. In H. Chick \& J. Vincent (Eds.), Proceedings of the 29th Conference of the International Group for the Psychology of Mathematics Education (Vol. 4, pp. 81-88). Melbourne: PME. Retrieved from https://www.emis.de/proceedings/PME29/PME29RRPapers/ PME29Vol4Pierce.pdf

Pierce, R., Stacey, K., \& Bardini, C. (2010). Linear functions: Teaching strategies and students' conceptions associated with $y=m x+c$. Pedagogies: An International Journal, 5(3), 202-215. https://doi.org/10.1080/1554480X.2010.486151

Rhodes-Houghton, R., Aird, J., Brownbill, C., Essack, R., Hoole, S., Kitto, A., ... Van Duyn, J. (2013). Classroom Mathematics Grade 9: Learner's Book. Johannesburg Heinemann.

Rider, R. (2007). Shifting from traditional to nontraditional teaching practices using multiple representations. Mathematics Teacher, 100(7), 494-500. Retieved from https://www.jstor.org/stable/i27972293

Rittle-Johnson, B., \& Schneider, M. (2014). Developing conceptual and procedural knowledge in mathematics. In R. Cohen Kadosh \& A. Dowker (Eds.), Oxford handbook of numerical cognition (pp. 1102-1118). Oxford: Oxford University Press.

Schwarz, B., \& Dreyfus, T. (1995). New actions upon old objects: A new ontological perspective on functions. Educational Studies in Mathematics, 29, 259-291. https://doi.org/10.1007/BF01274094

Shield, M., \& Dole, S. (2013). Assessing the potential of mathematics textbooks to promote deep learning. Educational Studies in Mathematics, 82(2), 183-199. https://doi.org/10.1007/s10649-012-9415-9

Shimizu, Y., Kaur, B., Huang, R., \& Clarke, D. (2010). The role of mathematical tasks in different cultures. In Y. Shimizu, B. Kaur, R. Huang, \& D. Clarke (Eds.), Mathematical tasks in classrooms around the world (pp. 9-14). Rotterdam: Sense Publishers.

Skemp, R. (1976). Relational understanding and instrumental understanding. Mathematics Teaching, 77, 20-26.

Stein, M.K., Smith, M.P., Henningsen, M., \& Silver, E. (2000). Implementing standardsbased mathematics instruction: A casebook for professional development. New York, NY: Teachers College Press.

Stylianides, G. (2014). Editorial: Textbook analyses on reasoning-and-proving: Significance and methodological challenges. International Journal of Education Research, 64, 63-70. https://doi.org/10.1016/j.ijer.2014.01.002 
Sullivan, P., Clarke, D., Clarke, B., \& O'Shea, H. (2010). Exploring the relationship between task, teacher actions, and student learning. PNA, 4(4), 133-142.
Retrieved from http://funes.uniandes.edu.co/663/1/Sullivan2010Exploring. pdf

Tripathi, N.P. (2008). Developing mathematical understanding though multiple representations. Mathematics Teaching in the Middle School, 13(8), 438-445. Retrieved from https://www.jstor.org/stable/i40053112

Valverde, G.A., Bianchi, L.J., Wolfe, R.G., Schmidt, W.H., \& Houng, R.T. (2002) According to the book: Using TIMSS to investigate the translation of policy into practice through the world of textbooks. Dordrecht: Kluwer Academic Publishers.
Van den Heuvel-Panhuizen, M. (2000). Mathematics education in the Netherlands: A guided tour. Freudenthal Institute CD-ROM for ICME9. Utrecht: Utrecht
University. Retrieved from http://www.fisme.science.uu.nl/staff/marjah/documents/ TOURdef+ref.pdf

Van Dyke, F., \& Craine, T.V. (1997). Equivalent representations in the learning of algebra. Mathematics Teacher, 90, 616-619. Retrieved from https://www.jstor. org/stable/27970324

Watson, A., \& Ohtani, M. (2015). Themes and issues in mathematics education concerning task design. In A. Watson \& M. Ohtani (Eds.), Task design in mathematics education: An ICMI study 22 (pp. 3-15). New York: Springer. https:// doi.org/10.1007/978-3-319-09629-2 